\title{
Kültürel Değerler Olarak Belirsizlikten Kaçınma ve Uzun Erimlilik ile Öğretmenlik Mesleğine Yönelik Tutum Arasındaki İlişki ${ }^{1}$
}

\author{
DOI: 10.26466/opus.930935 \\ * \\ Ahmet Saylık* \\ ${ }^{*}$ Dr. Öğr. Üyesi, Siirt Üniversitesi, Eğitim Fakültesi, Siirt/Türkiye \\ E-Posta: ahmetsaylik@gmail.com ORCID: 0000-0001-7754-2199 \\ ** Dr. Öğr. Üyesi, Kütahya Dumlupınar Üniversitesi, Eğitim Fakültesi, Kütahya/Türkiye \\ E-Posta: bunyaminhan@gmail.com ORCID: $\quad$ 0000-0003-0204-5686
}

Öz

Kültürel değerler, insanların inanç, tutum ve davranışlarım biçimlendiren, onlara yön verebilen bir yapıdadır. Belirsiz durumlar karşısında duyulan güvensizlik ve tehdit algısına yönelik tolerans düzeyini ifade eden belirsizlikten kaçınma ve zamanın (geçmiş, şimdi ve gelecek) nasıl değerlendirildiği ve atfedilen önem ile ilgili olarak uzun erimlilik önemli kültürrel değerlerdir. Bu kültürel değerlerin öğretmen adaylarının mesleki tutumlarımın biçimlenmesindeki rollerinin ne olduğunun tespit edilmesi bu araştırmanın temel amacını oluşturmaktadır. Araştırma genel tarama modeline göre desenlenmiş betimsel bir araştırmadır. Araştırmanın örneklem grubunu Siirt Üniversitesi Ĕ̆itim Fakültesi'nde öğrenim gören 380 öğrenci oluşturmaktadır. Veri toplama araçları olarak "Bireysel Kültür Değerleri Ölçeği" ile "Ö̈̆retmenliğe İlişkin Tutum Ölçeği" kullanılmıştır. Verilerin analizinde betimsel istatistikler, yüzde, frekans, t-testi, Tek-Yönlü Varyans Analizi (ANOVA) kullanılmıştır. Analizler sonucunda öğretmen adaylarının orta düzeyde belirsizlikten kaçınma ve yüksek düzeyde uzun erimlilik değerlerine sahip olduklar tespit edilmiştir. Öğretmen adaylarının öğretmenlik mesleğine yönelik yüksek düzeyde olumlu tutuma sahip olduklar ulaşılan bir diğer sonuçtur. Buna göre yüksek düzeyde belirsizlikten kaçınma eğiliminde olan öğretmen adaylarının mesleki tutumlarının daha olumlu olduğu; benzer şekilde, uzun erimli kültür değerlerine yüksek düzeyde sahip olan katılımcıların öğretmenlik mesleğine yönelik olumlu tutumlarının daha yüksek olduğu sonuçlarına ulaşılmıştır. Bulgulara dayalı olarak birtakım öneriler geliştirilmiştir.

Anahtar Kelimeler: Kültürel Değerler, Belirsizlikten Kaçınma, Uzun Erimlilik, Öğretmenlik Mesleği, Tutum.

\footnotetext{
${ }^{1}$ Bu çalışma 10-12 Haziran 2019 tarihinde Sirtt'te düzenlenen Uluslararası Sosyal ve Beşeri Bilimler Kongresinde sunulan "Öğretmenlik Mesleğine Yönelik Tutum Ile Belirsizlikten Kaçınma Arasındaki Ilişki" başııkı sözlü bildirinin genişletilmiş halidir.
} 


\title{
The Relationship between Attitude towards Teaching Profession and Uncertainty Avoidance and Long-Term Orientation as Cultural Values
}

\begin{abstract}
Cultural values are in a structure that can shape and guide people's beliefs, attitudes and behaviors. Uncertainty avoidance, which expresses the level of insecurity in the face of uncertain situations and tolerance towards threat perception, and long term orientation which expresses how the time (past, present and future) is evaluated and the attributed importance are among important cultural values. The main purpose of this study is to determine the roles of these cultural values in shaping prospective teachers' professional attitudes. The research is descriptive research designed according to the general survey model. The sample group of the study consists of 380 students studying at Siirt University Faculty of Education. As data collection tools, the "Individual Cultural Values Scale" and "Attitude Scale Towards Teaching" were used. Descriptive statistics, percentage, frequency, t-test, One-Way Analysis of Variance (ANOVA) were used in the analysis of the data. As a result of the analysis, it was determined that prospective teachers have a medium level of uncertainty avoidance and a high level of long-term orientation. Another result is that prospective teachers have a high level of positive attitude towards the teaching profession. In addition, it was found that the prospective teachers who tend to avoid high levels of uncertainty have more positive professional attitudes; similarly, the participants who have a high level of long-term orientation cultural values have higher positive attitudes towards the teaching profession. Some suggestions were developed based on these findings.
\end{abstract}

Keywords: Cultural Values, Uncertainty Avoidance, Long Term Orientation, Teaching Profession, Attitude. 


\section{Giriş}

Eğitim, bir ülkenin gelişmişlik düzeyini gösteren önemli göstergelerden biri olarak kabul edilmektedir. Bir ülkedeki eğitim sürecinin başarısı çoğunlukla öğretmenlerin etkililiğine bağlıdır. Öğretmenlik mesleğinin kendine özgü bazı özelliklerinden bahsetmek mümkündür. Bu meslek, fedakârlık, samimiyet ve fazladan çaba gerektiren bir meslektir. Bu nedenle başarılı bir öğretmenin mesleğini sevmesi ve mesleğe karşı olumlu tutuma sahip olması oldukça önemlidir. Öğretmenlerin etkililiğini etkileyen birçok faktörden bahsetmek mümkündür. Öğretmenlerin hem öğretme yeterlilikleri hem de kişisel özellikleri süreçte önemli rol oynamaktadır. Bu konuda Trivedi (2012) öğretmenlerin inanç, görüş ve tutumlarının hem öğretme sürecini hem de davranışlarını etkilediğini belirtmektedir. Benzer şekilde Kontaş (2016) eğitimin kalitesinin öğretmenlerin mesleki ve kişisel özellikleriyle doğrudan ilişkili olduğunu ifade etmektedir. Cristina-Corina ve Valerica'ya (2012) göre öğretmenlerin tutum ve algıları etkili öğretimin temelini oluşturmaktadır. Yine Şahin (2010) öğretmen niteliklerinin yanı sıra mesleğe yönelik tutumların süreçteki önemine dikkat çekmektedir. Dolayısıyla öğretmenin mesleğe yönelik tutumu, öğretmenin başarısını ve verimliliğini etkilemektedir (Güneyli ve Aslan, 2009; Sharbain ve Tan, 2012). Pancholi ve Bharwad (2015) olumlu bir tutumun işi tatmin edici ve profesyonel olarak ödüllendirici yaptığını, bunun yanında, olumsuz bir tutumun öğretim işini daha zor, sıkıcı ve tatsız hale getirdiğini ifade etmektedir.

Öğretmenlerin mesleğe karşı olumlu tutum kazanacakları en uygun dönem, öğretmenliğe hazırlandıkları lisans eğitimi sürecidir. Bu bağlamda öğretmen adaylarının mesleğe karşı tutumlarının büyük ölçüde oluştuğu bu sürecin yapılandırılması önemli görülmektedir. Akbulut ve Karakuş (2011) öğretmen adaylarının öğretmen yetiştirme sürecinde öğretmenlik mesleğine yönelik tutum kazandıklarını ileri sürmektedirler. Bu konuda Üstüner (2017) öğretmen yetiştirme sürecinin eğitim sisteminin kritik unsuru olduğunu ifade etmektedir. Benzer şekilde Alkhateeb (2013) başarılı bir eğitim sağlamak için öğretmen adaylarının profesyonel öğretmenler olarak yetiştirilmesi gerektiğini vurgulamaktadır. Musa ve Bichi (2015) öğretmen yetiştirme 
programlarının mesleğe karşı olumlu bir tutum kazandıracak şekilde tasarlanmasını önermektedir. Buna göre öğretmen adaylarının mesleğe hazırlanma sürecinde olumlu tutum kazanmaları eğitim sürecinin başarısı ve etkililiği noktasında oldukça kritik bir öneme sahip olduğu görülmektedir. $\mathrm{Bu}$ bakımdan bu süreçteki öğretmen adaylarının tutumların belirlemek, bu tutumlara etki eden faktörleri ortaya koymak sürecin başarısı adına önemli adımlar olarak değerlendirilmektedir.

Bir toplumda bireylerin mesleki tutumlarının, çalışmaya ve iş yaşamına yükledikleri anlam ve bunlara ilişkin beklentilerinin bireysel gibi görünse de makro düzeydeki toplumsal kültür yapısı ve değerlerinden beslendikleri ve bunun sosyalizasyon sürecinde oluşturulduğu düşünülmektedir. Bu anlamda toplumun belirsizlik karşısındaki tolerans düzeyi ve zamanı (geçmiş, şimdi ve gelecek) hayatında nasıl anlamlandırdığı ve değer yüklediği gibi ulusal kültür değerlerin mesleki kaygı, tutum ve anlamlar silsilesini etkilediği düşünülmektedir.

Belirsizlikten kaçınma kültür boyutu, düzensizlik, belirsizlik ve tutarsızlık karşısında insanların hissettikleri tehdit ve endişeye karşın yasal düzenlemelere duydukları ihtiyaç düzeyini ifade eder (Hofstede, 2001; Javidan ve House, 2001). Uzun-kısa erimlilik kültür değeri ise toplumların zamanı (geçmiş, bugün ve gelecek) nasıl anlamlandırdıkları, bunların önem sırası ve ağırlığını belirtir (Mosakowski ve Earley 2000; Spears, Lin ve Mowen 2000).

$\mathrm{Bu}$ araştırmanın temel amacl, öğretmen adaylarının öğretmenlik mesleğine yönelik tutumları ile kültürel birer değer olarak belirsizlikten kaçınma ve uzun erimlilik düzeyleri arasındaki ilişkiyi ortaya koymaktır. Bunun yanı sıra toplumsal cinsiyet rolleri bağlamında Türkiye'de öğretmenlik mesleğinin daha çok kadın mesleği olarak düşünülmesine bağlı olarak öğretmen adaylarının cinsiyetlerinin hem kültürel değişkenler hem de öğretmenlik mesleği tutumunda anlamlı farklılık ortaya koyup koymadığı incelenmiştir. Katılımcıların öğretmenliği kaçıncı sırada tercih ettikleri, öğretmenliği benimseyip benimsemedikleri, hangi alan/bölümde öğretmen adayı oldukları şeklindeki kişisel tercih ve özelliklerin öğretmenlik mesleğine ilişkin tutumlarındaki belirleyiciliği ortaya koymak araştırmanın alt amaçları arasındadır. Benzer şekilde katılımcının yaşamını daha çok nasıl bir 
yerleşim yerinde geçirdikleri, toplumsal sosyalizasyonlarını büyük oranda etkilediğinden hareketle kültürel değerlerin biçimlenmesindeki rolü olabileceği düşünülmüş ve araştırmadaki etkileri ortaya konmaya çalışılmıştır. Bu amaçla aşağıdaki sorular araştırılmıştır;

1. Öğretmen adaylarının öğretmenlik mesleğine yönelik tutumları, belirsizlikten kaçınma ve uzun erimlilik kültür değerleri ne düzeydedir?

2. Öğretmen adaylarının öğretmenlik mesleğine yönelik tutumları, belirsizlikten kaçınma ve uzun erimlilik kültür değerleri; cinsiyet, öğretmenliği tercih etme nedeni, öğretmenliğin kaçıncı tercihi olduğu, yaşamını daha çok geçirdiği yerleşim yeri, bölüm ve öğretmenlik okumayı tavsiye etme değişkenlerine göre anlamlı düzeyde değişmekte midir?

3. Öğretmenlik mesleğine yönelik tutum ile belirsizlikten kaçınma ve uzun erimlilik kültür değerleri arasında anlamlı bir ilişki var midir?

\section{Literatür Taraması}

\section{Öğretmenlik mesleğine yönelik tutum}

Öğretmenlerin sahip oldukları kişisel özellikler ve mesleğine karşı tutumlarının başarılı bir öğretmenlik için önemi araştırmalarda vurgulanan bir konudur. İlgili alanyazın başarılı bir öğretmenin mesleğini sevmesi ve mesleğe karşı olumlu tutuma sahip olması gerektiğini ortaya koymaktadır. Tutum kavramı, belirli bir nesneyle ilişkili inançlar, alışkanlıklar ve güdüler olarak tanımlanabilir (Barwal, 2011). Robbins ve Judge, (2012) tutumu; nesneler, bireyler veya olaylar hakkındaki olumlu veya olumsuz değerlendirmelerin ifadesi olarak tanımlamaktadır. Başka bir ifade ile tutum, bireyin herhangi bir duruma, olaya ya da nesneye yönelik olumlu ya da olumsuz tepkileri olarak tanımlanır (Akbulut ve Karakuş, 2011; Andronache, vd., 2014). Babu ve Raju'ya (2013) göre tutum, bireyin belirli bir duruma hazır hale gelmesi için zihinsel süreçlerin ve içsel eğilimin düzenlenmesi işlevi görür. Mesleki tutum ise bireyin duyguları, davranışları ve mesleğine bağl1lığ1 (Chakraborty ve Mondal, 2014) olarak değerlendirilmektedir. Mesleğe 
yönelik tutumlar genellikle mesleği yapmaktan zevk almak, mesleğine bağlılık, mesleğin sosyal olarak yararlı olduğunun farkında olmak ve mesleki gelişimini artırmaya inanmakla ilgilidir (Parvez ve Shakir, 2013). Buna göre öğretmenlerin mesleğe karşı tutumları mesleklerini icra etme sürecindeki başarının temel belirleyicisi olarak karşımıza çımaktadır.

Öğretmenlik mesleği hem bilgi ve beceri gibi bilişsel yeterlikleri hem de tutum ve davranışlar gibi duyuşsal yeterlikleri gerektirir (Bektaş ve Nalçacı, 2012). Oral (2004) öğretmenlik mesleğinde bilgi ve becerilerin yanında duyuşsal özellikler kapsamında tutumlarının da etkili olduğunu belirtmektedir. Barwal, (2011) öğretmenlik mesleğinin, öğretmenlerin eğitim ortamında deneyimlerine karşı duyuşsal veya duygusal tepkilerinin bir parçası olduğunu ileri sürmektedir. $\mathrm{Bu}$ nedenle, öğretmenlerin öğrencilerini öğrenme konusunda motive etmesinde tutumun etkili olduğu (Sarkar ve Behera, 2016) ortaya konulmaktadır. Üstüner (2017) öğretmenlerin mesleğe yönelik tutumunun sınıf ortamında öğretmen davranışını belirleyen temel faktörlerden biri olduğunu ifade etmektedir. Kontaş'a göre (2016) de mesleğe yönelik tutum, mesleki davranışın bir göstergesidir ve öğretmenlerin mesleki algılarını yansıtır. Böylece etkili öğretimine ancak öğretmenlik mesleğine yönelik olumlu tutumun sonucunda ulaşlabileceği (Banerjee ve Behera, 2014) ifade edilebilir. Güneyli ve Aslan (2009) mesleğine olumlu yaklaşan öğretmenin mesleğinden zevk aldığını, kendini mesleğine adadığını, mesleğinin sosyal açıdan gerekli ve önemli olduğunun bilincinde olduğunu belirtmektedir. Mesleğe karşı olumlu tutum, öğretmenin sinıfta öğrenci dostu bir ortam geliştirmesinde (Bhargava ve Pathy, 2014) ve öğrencilere karşı insancıl tutum ve davranışlar göstermesinde etkili olmaktadır (Oğuz ve Kalkan, 2011). Yaakub (1990) öğrencilerine karşı iyi bir eğilime sahip öğretmenlerin olumlu tutumu yansıttıklarını, zayıf eğilimli ögrretmenlerin ise olumsuz tutuma sahip olduklarını ortaya koymuştur. Bu bağlamda mesleğe yönelik olumlu tutumlar öğretmenin sınıf davranışına da yansır ve öğretmen rolünü daha iyi yerine getirmesini sağlar (Şahin, 2010). Chakraborty ve Mondal'a (2014) göre olumlu tutuma sahip öğretmen daha iyi performans ve çaba gösterir. Benzer şekilde Egwu (2015) da olumlu tutumun öğretmenlerin eğitim sürecini doğru bir şekilde gerçekleştirmelerini ve ileriye yönelik donanımlı hale gelmelerini 
sağladığını vurgulamaktadır. Ayrıca, Bilgin ve Aykaç (2016) öğretmenlik mesleğine yönelik olumlu tutuma sahip öğretmen adaylarının mesleki yaşamlarında başarılı öğretmenler olacaklarının öngörülebileceğini belirtmektedir. $\mathrm{Bu}$ nedenle öğretmenlik mesleğine yönelik olumlu tutumlar, etkili öğretim ve öğretmen başarısının önemli bir unsuru olarak görülebilir. Ancak tutumların, bir parçası olunan sosyolojik yapı ile organik ilişkisi göz ardı edilmemelidir. Toplumun belirsizlikten kaçınma ve uzun-kısa erimli yapısının bireysel anlamda edinilen mesleki tutumlarda etkili olduğu düşünülmektedir.

\section{Belirsizlikten kaçınma}

Geleceğin belirsizliği bütün toplumlar için söz konusu iken bu belirsizlikler karşısında toplumların geliştirdiği refleks belirsizliklerle nasıl yüzleşildiği ve baş edildiği, kültürel bir tavırdır ve kültürler arasındaki farklılaşmanın önemli bir kaynağıdır. Bu nedenle belirsizlik kaynaklı duygu durumları ve bununla nasıl baş edildiği, kültürel yolla öğrenilmektedir (Hofstede, Hofstede ve Minkov, 2010). Toplumların, dayanılmaz bir kaygı kaynağı olan aşırı belirsizlik karşısındaki tavırları teknoloji, hukuk ve din alanlarındaki farklı yaklaşımlarıyla kendini göstermektedir. Doğanın kaynağı olduğu belirsiz durumlar için teknoloji, insanların toplumsal yaşam içerisindeki davranışlarında yatan belirsizlikler için hukuk ve aşkın bir güce sığınarak geleceğin belirsizliğini kontrol etme aracı olarak da din-inanç tarih boyunca her toplumda süregelmiştir (Hofstede, 1983; Hofstede, 2001). Ancak bu üç alana yüklenen anlamın derinliği ve bunlara sığınma biçimi kültürleri birbirinden ayırmaktadır.

İnsanların düzenli ve tutarlı oluşa, kanun ve nizama duyulan ihtiyacın düzeyine ilişkin olan (Javidan ve House, 2001) belirsizlikten kaçınma kültür boyutu, bazı toplumlarda yüksek iken bazılarında düşüktür. Belirsizlikten kaçınmanın düşük olduğu toplumlarda kaygı düşük düzeydedir. Farklılıkları bir tehdit unsuru olarak görmezler ve hoşgörü gösterirler. Bu toplumlarda güven hissi hâkimdir. Bu nedenle, ihtiyaç halinde buna muktedir olmakla birlikte aşırı çalışmak anlamlı değildir (Hofstede, 1983; Hofstede vd., 2010). Oysa belirsizlikten kaçınmanın yüksek olduğu toplumlarda istikrarlı bir kariyer sağlama, 
daha formel normlar oluşturma, alışılmışın dişındaki davranış ve fikirleri tahammülsüzlük söz konusudur ve doğruluğuna mutlak biçimde inanılan değerler ve inançlar yoluyla müphem durumlarla baş edilmeye çalışılır. Bu kültürel atmosferde hayat hızlı akıp gider ve vakit nakittir anlayışı egemendir. Yüksek kaygıdan hareketle sıkı çalışma ve saldırgan eğilimi güçlüdür (Hofstede, 1980; Hofstede vd., 2010). Gençler belirsizlikle birlikte yaşamlarını planlarken temkinli davranır ve risk almaktan kaçınırlar.

Belirsizlikten kaçınma düzeyinin farklılığı okul ve eğitim yapısını da farklılaştırmaktadır. Bu farklılıklar Tablo 1'de verilmektedir.

Tablo 1. Düşük ve Yüksek Belirsizlikten Kaçınmanın olduğu Toplumlarda Eğitim ve Okullar

\begin{tabular}{|c|c|}
\hline Düşük Belirsizlikten Kaçınma & Yüksek Belirsizlikten Kaçınma \\
\hline \multicolumn{2}{|c|}{ Öğrencilerin beklentileri esnek öğrenme ve tartı̧maÖğrenciler yapılandırılmış } \\
\hline $\begin{array}{l}\text { ağırlıklı ortamlardır. } \\
\text { Ögrretmenler "bilmiyorum" diyebilir. }\end{array}$ & $\begin{array}{l}\text { doğru cevaplar peşindedir. } \\
\text { Öğretmenlerin bütün soruların cevaplarını bilmesi } \\
\text { beklenmektedir. }\end{array}$ \\
\hline Öğrenciler gerçeğin göreceli olabileceğini öğ & jğrenirler. ̈̈̆ğrenciler gerçeğin mutlak olduğunu öğrenirler. \\
\hline $\begin{array}{l}\text { Öğrenciler kazanımlarını kendi yet } \\
\text { bağlarlar. }\end{array}$ & $\begin{array}{c}\text { eteneklerineÖğrenciler başarılarını gayret, şartlar ve şansa } \\
\text { bağlarlar. }\end{array}$ \\
\hline $\begin{array}{l}\text { Çocukların öz yeterlikleri yüksektir. } \\
\text { Ögrretmenler, ebeveynlerin fikirlerini } \\
\text { çalışmaktadırlar. }\end{array}$ & $\begin{array}{l}\text { Çocukların öz yeterlikleri düşüktür. } \\
\text { öğrenmeyeEbeveynler öğretmenlerin uzantısı olarak görülür. }\end{array}$ \\
\hline Kız öğrenciler için serbestlik önemlidir. & $\begin{array}{l}\text { Kız öğrenciler için geleneksel rol modelleri söz } \\
\text { konusudur. }\end{array}$ \\
\hline Öğretmenler ebeveynleri sürece dahil eder. & Öğretmenler ebeveynleri bilgilendirir. \\
\hline
\end{tabular}
Kaynak: Hofstede, 2001, 169 ve Hofstede vd., 2010, 208.

Tabloda görüldüğü gibi belirsizlik karşısında takınılan toplumsal tavır beraberinde eğitim sistemlerine ilişkin, müfredat, mevzuat, öğretmen-öğrenci ilişkileri, bilgiye bakış gibi hususları da etkileyebilmektedir.

Türkiye, Hofstede'nin araştırma bulgularına göre ortalamanın 56 olarak belirlendiği skalada 85 puanla belirsizlikten kaçınmanın yüksek olduğu bir kültürel yapı görünümündedir. Aynı araştırmada İsveç ve Danimarka en düşük, Yunanistan ise en yüksek puana sahiptir (Hofstede vd., 2010, 192). Benzer bulgular Türkiye'nin de örnekleminde yer aldığ çok uluslu kültürlerarası başka çalışmalarda da (House, Hanges, Javidan, Dorfman ve Gupta, 2004; Ronen, 1986) ortaya konulmuştur. 
Türkiye'deki sosyolojik yapı incelendiğinde belirsizlikten kaçınma eğiliminin oldukça yüksek olduğunu gösteren durumlar söz konusudur. Örneğin 'yaşam boyu istihdam' anlayışı oldukça güçlüdür. Bu anlayışla belirsizlik giderilmeye çalışılır. Öte yandan düşük belirsizlikten kaçınma kültürünün baskın olduğu toplumlarda iş değiştirme ve işler arasında geçiş hareketliliğinin fazla olması söz konusudur (Sargut, 2015). Türkiye'de "devlet memurluğu" ve "kadrolu iş"e yüklenen aşırı anlam ve değer toplumsal yapıdaki belirsizliğin yansıması olarak değerlendirilebilir.

\section{Uzun Erimlilik (Long-Term Orientation)}

Toplumlar arasındaki kültürel farklılığın önemli bir boyutu da uzun erimliliktir. Bu kültürel değer, insanların zamana nasıl anlam yükledikleri (Mosakowski ve Earley, 2000), beklenti, hedef veya planlarının uzun veya kisa erimli olmasına göre nasıl anlamlandırdıklarına ilişkindir. Uzun dönem yönelimli toplumların planları geleceğe ilişkindir. Daha pragmatik davranırlar. İstikrar, süreklilik arayışları güçlüdür. Tasarruf etme oldukça önemsenir. Kısa erimli kültürlerde ise gelecekten ziyade geçmiş veya şimdiye odaklı değerler ön plandadır. Bu kültürlerde gelenek-göreneklere saygı ve kolektif sorumluluklar belirgin ve güçlüdür (Hofstede vd., 2010).

Hofstede'nin araştırma sonuçları, Türkiye'yi uzun erimlilik boyutunda 76 ülke içerisinde 47 . sırada ortaya yakın olmakla birlikte kısa erimli olarak konumlandırmaktadır (Hofstede vd., 2010, 257). Bu boyutta puanın düşüklügüu, toplumsal değişime şüpheli ve temkinli yaklaşımı, geleneksel değerleri ise koruma ve sürdürme eğilimini ön plana çıkarmaktadır. Bu boyutta yüksek puan ise daha pragmatik bir kültürel yaklaşımı ve buna bağlı olarak çağdaş eğitimi geleceğe hazırlanmanın etkin bir yolu inancını ifade etmektedir.

\section{Yöntem}

$\mathrm{Bu}$ araştırma betimleyici bir araştırma olup araştırmada "ilişkisel tarama" deseni kullanılmıştır. Bu bağlamda kültürel değerler olan 
belirsizlikten kaçınma ve uzun erimlilik değerlerinin öğretmenlik tutumu ile ilişkisi incelenmiştir.

\section{Veri Toplama Araçları}

Araştırmada Yoo, Donthu ve Lenartowicz (2011) tarafından geliştirilmiş ve Saylık (2019) tarafından Türkçeye uyarlama çalışması yapılan "Bireysel Kültür Değerleri Ölçeği (CVSCALE-Individual Cultural Values Scale)" kullanılmıştır. Beşli likert tipindeki ölçekten toplam puan üretilememektedir. Ölçek her biri bağımsız beş alt ölçekten ve toplamda 26 maddeden oluşmaktadır. Alt ölçeklerden güç mesafesi ve belirsizlikten kaçınma 5, kolektivizm ve kısa erimlilik 6 ve erillik 4 madde ile açıklanmaktadır. $\mathrm{Bu}$ araştırmada sadece Belirsizlikten kaçınma ve Uzun erimlilik boyutları kullanılmıştır. Ancak veriler toplanırken geçerliğine hizmet edeceği düşüncesiyle ölçeğin tamamı katılımcılara sunulmuştur. Araştırmada kullanılan alt ölçekler zıt kutuplu bir yapıda olup düşük belirsizlikten kaçınmaya karşı yüksek belirsizlikten kaçınma ve uzun erimliliğe karşı kısa erimliliği ölçmektedir. Ölçeklerden elde puanların yüksekliği, yüksek belirsizlikten kaçınma ve uzun erimliliği göstermektedir. Ölçeğin orijinaline ilişkin analizlere göre belirsizlikten kaçınma .71 ve kısa-uzun erimlilik ise .71 alfa katsayssma sahiptir. Yoo, Donthu ve Lenartowicz (2011) ölçeğin toplam varyansını \% 44.5, Hofstede (2001) ise \%49 olarak tespit etmişlerdir. $\mathrm{Bu}$ araştırmada da belirsizlikten kaçınma için Cronbach alpha değeri .64 ve uzun erimlilik için ise .70 olarak tespit edilmiştir.

Öğretmenlik Mesleğine Yönelik Tutum (ÖMYT) Ölçeği: Araştırmada verileri toplamak için Erkuş, Sanlı, Bağlı ve Güven (2000) tarafından geliştirilen "Öğretmenliğe İlişkin Tutum Ölçeği" kullanılmıştır. 23 maddeden oluşan ölçeğin 10 maddesi olumlu, 13 maddesi olumsuzdur. Araştırmacılar (2000) ölçeğin Cronbach alpha değerini .99 olarak tespit etmişlerdir. $\mathrm{Bu}$ araştırma kapsamında yapılan analizlerde Cronbach alpha değerinin .90 olduğu tespit edilmiştir. Dolayısıyla her iki ölçeğin güvenilir olduğu kanaatine varılmıştır. Her iki ölçek de beşli liket tipinde düzenlenmiş olup "hiç katılmıyorum"dan "tamamen katılıyorum"a doğru derecelendirilmiştir. 


\section{Evren ve Örneklem}

Araştırmanın hedef evreni, Siirt Üniversitesi Eğitim Fakültesi'nde öğrenim görmekte olan öğrencilerden oluşmaktadır. Siirt Üniversitesi öğrenci işlerinden alınan güncel verilere göre Eğitim Fakültesi bünyesinde bulunan, Sınıf, Fen Bilgisi, Türkçe, İlköğretim Matematik, Sosyal Bilgiler Öğretmenlikleri ve Bilgisayar ve Öğretim Teknolojileri Eğitimi bölümlerinde 1867 öğrenci öğrenim görmektedir. Araştırmada gerekli verileri toplamak üzere "tabakalı örnekleme" yöntemi uygulanmıştır. Araştırmanın örneklemi Tablo 2'de sunulmuştur.

Tablo 2. Araştırma Örneklemi

\begin{tabular}{lcccccc}
\hline $\begin{array}{l}\text { Siirt Üni. Ĕgitim Fak. } \\
\text { Bölümleri }\end{array}$ & 1. Sınıf & 2. Sınıf & 3. Sınıf & 4. Sınıf & Öğrenci (\%) & Öğrenci(n) \\
\hline Böte & 3 & 24 & 56 & 82 & 9 & 34 \\
Fen B. Öğrrt. & 28 & 25 & 82 & 105 & 13 & 49 \\
Illk. Mat. Öğrt. & 63 & 59 & 59 & 138 & 17 & 65 \\
Sinff Öğrt. & 110 & 111 & 106 & 133 & 25 & 93 \\
Sosyal B. Öğrt. & 107 & 91 & 92 & 104 & 21 & 80 \\
Türkçe Öğrt. & 47 & 59 & 94 & 89 & 15 & 59 \\
Toplam & 358 & 369 & 489 & 651 & 100 & 380 \\
\hline
\end{tabular}

Araştırmada, Siirt Üniversitesi Eğitim Fakültesindeki her bölüm bir tabaka olarak düşünülmüştür. Daha sonra her bölümden kaç öğrencinin örnekleme dahil edileceği, bölümlerdeki öğrenci sayısının toplam öğrenci sayısı oranına göre hesaplanmıştır. Bölüm bazlı belirlenen toplam öğrenciler her sınıf seviyesinden eşit sayıda alınmıştır. Öğrenciler arasından katılımcılar ise tesadüfi yolla seçilmişlerdir.

Tablo 3. Katılımcıların özellikleri

\begin{tabular}{llll}
\hline Değişken & Grup & $\mathbf{n}$ & $\mathbf{\%}$ \\
\hline \multirow{2}{*}{ Cinsiyet } & Kadın & 230 & 60,5 \\
& Erkek & 150 & 39,5 \\
Öğretmenliği tercih etme & İsteğimle & 245 & 64,5 \\
nedeni & Çevre/Aile Baskısı & 87 & 22,9 \\
Öğretmenlik kaçıncı & Diğer & 48 & 12,6 \\
tercih & İlk 5 tercih & 240 & 63,2 \\
Yaşamını daha çok & Altıncı ve sonrası tercih & 140 & 36,8 \\
nerede geçirdiği & Köy/Kasaba/İlçe & 171 & 45,0 \\
& Şehir/Büyükşehir & 209 & 55,0 \\
Bölüm & Türkçe Ö. & 34 & 8,9 \\
& Sosyal Bilgiler Ö. & 115 & 30,3 \\
& İlköğretim Matematik Ö. & 53 & 13,9
\end{tabular}




\begin{tabular}{llll} 
& Fen Bilgisi Ö. & 49 & 12,9 \\
& Sinıf Ö. & 96 & 25,3 \\
& BÖTE Ö. & 33 & 8,7 \\
Öğretmenliği tavsiye & Evet & 276 & 72,6 \\
etme & Hayır & 104 & 27,4 \\
& Toplam & 380 & 100 \\
\hline
\end{tabular}

Tablo 3 incelendiğinde, katılımcıların çoğunluğunun kendi isteği ile eğitim fakültesini ilk 5 tercihi arasında gösterenlerden oluştuğu görülmektedir. Yaşamını daha çok şehir/büyükşehirlerde geçiren katılımcıların daha fazla olduğu ve katılımcıların \%72'sinin öğretmenliği tavsiye ettiği gözlenmektedir. Katılımcıların \%60,5'ini kadınlar oluşturmaktadır.

\section{Verilerin Analizi}

Araştırma verileri bilgisayar paket programları yoluyla analiz edilmiştir. Öncelikle verilerin normalliği test edilmiştir. Buna göre mesleğe yönelik tutum için (Skewness = ,137; Kurtosis = -,876); belirsizlikten kaçınma için (Skewness = -,027; Kurtosis = -,466); Uzun erimlilik için (Skewness = ,170; Kurtosis = -,461) olarak hesaplanmıştır. Bu değerler -2 ile +2 aralığında olduğu için verilerin normal dağılım gösterdiği varsayılmıştır. Bundan dolayı analizlerde parametrik testler (t-Testi, ANOVA) kullanılmıştır. Araştırmanın katılımcı sayısının göreli büyüklüğü $(n=380)$ de verilerin normal dağıldığına ilişkin kanıyı güçlendirmiştir.

Verilerin güvenirliği Cronbach's Alpha katsayıları hesaplanarak ortaya konulmuştur. Buna göre Cronbach's Alpha katsayısı mesleğe yönelik tutum için ,90; belirsizlikten kaçınma için ,65; Uzun erimlilik için ,70 olarak hesaplanmıştır. $\mathrm{Bu}$ değerler kabul edilebilir değer aralığındadır. Araştırmada belirsizlikten kaçınma ve uzun erimlilik kültürel değerleri ile öğretmenlik mesleğine karşı tutum arasındaki ilişkileri tespit etmek amaciyla alt grup- üst grup ortalamaları hesaplanmıştır. Ölçekler uzun erimliliğe karşı kısa erimlilik ve yüksek belirsizlikten kaçınmaya karşı düşük belirsizlikten kaçınma şeklinde zıt kutuplu yapıdadır. Bu nedenle bu grupların hesaplanmasında verilerin ranjı hesaplanmış ve alt grup- üst gruplardaki katılımcıların mesleğe karşı tutum ortalamaları karşılaştırılmıştır. Ölçekler zıt kutuplu 
olduğundan yani "belirsizlikten kaçınma-belirsizliği kabullenme" ve "uzun erimliliğe karşı kısa erimlilik" görüşlerine dayandığı için veri setinin ranj1 dikkate alınarak \%27'lik en yüksek ve \%27'lik en düşük ortalamaya sahip katılımcıların görüşleri arasında karşılaştırma yapılarak katılımcı görüşleri arasındaki farklılıklar daha net ortaya konulmuştur.

\section{Bulgular}

Araştırmada elde edilen bulgular sırasıyla sunulmaktadır.

\section{Belirsizlikten Kaçınmaya İlişkin Bulgular}

Araştırma kapsamında kendilerinden veri toplanan öğretmen adaylarının belirsizlikten kaçınmaya yönelik görüşleri hesaplanmış ve bulgular aşağıda verilmiştir.

Tablo 4. Belirsizlikten kaçınmaya yönelik bulgular

\begin{tabular}{|c|c|c|c|}
\hline Boyut & Maddeler & $\mathbf{X}$ & ss \\
\hline \multirow{6}{*}{ 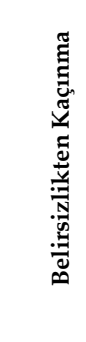 } & $\begin{array}{l}\text { "Kurallar ve düzenlemeler benden ne beklendiğini anlamamı sağladığı için } \\
\text { önemlidir." }\end{array}$ & 3,05 & 1,27 \\
\hline & "Talimatları ve prosedürleri sıkı sıkıya takip etmek önemlidir." & 3,23 & 1,26 \\
\hline & $\begin{array}{l}\text { "İşimde kullanmam gereken prosedürlerin standartlaştırılmasını yararlı } \\
\text { buluyorum." }\end{array}$ & 3,21 & 1,31 \\
\hline & $\begin{array}{l}\text { "Benden tam olarak ne istendiğini bilebilmem için açı biçimde belirtilen } \\
\text { talimatlar gereklidir." }\end{array}$ & 3,26 & 1,23 \\
\hline & “Yapılacak uygulamaların talimatlarla açıklanması önemlidir." & 3,77 & 1,24 \\
\hline & Belirsizlikten Kaçınma Toplam & 3,31 & 82 \\
\hline
\end{tabular}

Tablo 4'te görüldüğü gibi öğretmen adaylarının belirsizlikten kaçınma görüş ortalaması $(X=3,31)$ olarak hesaplanmıştır. Buna göre öğretmen adaylarının orta düzeyde belirsizlikten kaçınma eğilimine sahip oldukları söylenebilir.

Araştırmada, öğretmen adaylarının belirsizlikten kaçınma eğilimleri cinsiyet, öğretmenliği tercih etme nedeni, öğretmenliği tercih sırası, yaşamını daha çok nerede geçirdiği, öğretmenliği tavsiye etme durumu 
ve branş gibi bazı değişkenler bakımından incelenmiş ve buna yönelik bulgular aşağıda verilmiştir.

Tablo 5. Bazı değişkenlere göre belirsizlikten kaçınma eğilimleri

\begin{tabular}{|c|c|c|c|c|c|c|c|c|}
\hline \multirow{11}{*}{ 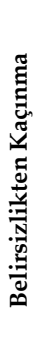 } & Değişken & Grup & $\mathbf{n}$ & $X$ & Ss & $\mathrm{t}$ & Sd & $\mathrm{p}$ \\
\hline & \multirow[t]{2}{*}{ Cinsiyet } & Kadın & 230 & 3,31 & 82 & \multirow[t]{2}{*}{ 236 } & \multirow[t]{2}{*}{378} & \multirow[t]{2}{*}{814} \\
\hline & & Erkek & 150 & 3,29 & ,82 & & & \\
\hline & \multirow{2}{*}{$\begin{array}{l}\text { Öğretmenliği tercih } \\
\text { etme nedeni }\end{array}$} & İsteğimle & 245 & 3,33 & ,83 & \multirow[t]{2}{*}{,889 } & \multirow[t]{2}{*}{378} & \multirow[t]{2}{*}{,375 } \\
\hline & & Diğer (Çevre/Aile) & 135 & 3,26 &, 80 & & & \\
\hline & \multirow{2}{*}{$\begin{array}{l}\text { Öğretmenlik kaçıncı } \\
\text { tercih }\end{array}$} & İlk 5 Tercih & 240 & 3,35 & 84 & \multirow[t]{2}{*}{1,296} & \multirow[t]{2}{*}{378} & \multirow[t]{2}{*}{ 196 } \\
\hline & & 6 ve sonrası tercih & 140 & 3,23 & ,77 & & & \\
\hline & \multirow{4}{*}{$\begin{array}{l}\text { Yaşamını daha çok } \\
\text { nerede geçirdiği } \\
\text { Öğretmenliği tavsiye } \\
\text { etme }\end{array}$} & Köy/Kasaba/İlçe & 171 & 3,35 &, 84 & \multirow[t]{2}{*}{,909 } & \multirow[t]{2}{*}{378} & \multirow[t]{2}{*}{,364 } \\
\hline & & Şehir/Büyükşehir & 209 & 3,27 &, 80 & & & \\
\hline & & Evet & 276 & 3,35 &, 82 & \multirow[t]{2}{*}{1,613} & \multirow[t]{2}{*}{378} & \multirow[t]{2}{*}{ 108 } \\
\hline & & Hayır & 104 & 3,20 & 82 & & & \\
\hline
\end{tabular}

Tablo 5'de görüldüğü gibi öğretmen adaylarının belirsizlikten kaçınma eğilimleri katılımcıların cinsiyet, öğretmenliği tercih etme nedeni, öğretmenliği tercih sırası, öğretmenliği tavsiye etme durumu, yaşamını geçirdiği yer bakımından anlamlı olarak farklılaşmamaktadır.

Tablo 6. Bölümlere Göre Belirsizlikten Kaçınma

\begin{tabular}{llllll}
\hline & $\mathbf{N}$ & $\mathbf{X}$ & Ss & F & p \\
\hline 1. Türkçe Ö. & 34 & 3,22 &, 73 & & \\
2. Sosyal Bilgiler Ö. & 115 & 3,36 &, 89 & & \\
3. İlköğretim Mat. Ö. & 53 & 3,44 &, 56 & 1,646 & \multirow{2}{*}{147} \\
4 Fen Bilgisi Ö. & 49 & 3,41 &, 71 & & \\
5. Sinuf Ö. & 96 & 3,25 &, 92 & & \\
6. BÖTE Ö. & 33 & 3,01 &, 85 & & \\
Toplam & 380 & 3,31 &, 82 & & \\
\hline
\end{tabular}

Tablo 6'da görüldüğü gibi branşlarına göre katılımcıların görüşleri arasında anlamlı fark saptanmamıştır.

\section{Uzun Erimlilik Görüşlerine İlişkin Bulgular}

Araştırma kapsamında kendilerinden veri toplanan öğretmen adaylarının uzun erimlilik eğilimlerine yönelik görüşleri hesaplanmış ve bulgular aşağıda verilmiştir. 
Tablo 7. Uzun erimlilik görüşlerine yönelik bulgular

\begin{tabular}{llll}
\hline Boyut & Maddeler & X & ss \\
\hline & "İnsan sahip olduğu parayı iyi yönetmeli ve dikkatli harcamalıdır." & 3,65 & 1,27 \\
& "Bütün engellere rağmen amaçlar doğrultusunda kararllıkla yola & 3,62 & 1,30 \\
$\quad$ devam edilmelidir." & 3,09 & 1,24 \\
$\quad$ "Uzun vadeli planlama yapmak önemlidir." & 3,30 & 1,26 \\
$\quad$ "Bireylerin kararlı ve istikrarlı olmaları önemlidir." & 3,34 & 1,29 \\
$\quad$ "Gelecekte başarılı olmak için, gününü gün etmekten & 3,62 & 1,21 \\
$\quad$ kaçınlmalıdır." & 3,43 &, 80 \\
\hline
\end{tabular}

Tablo 7'de görüldügü gibi öğretmen adaylarının uzun erimlilik görüş ortalaması $(X=3,43)$ olarak hesaplanmıştır. Buna göre öğretmen adayları yüksek düzeyde uzun erimlilik eğilimine sahip oldukları söylenebilir.

Araştırmada, öğretmen adaylarının uzun erimlilik eğilimleri cinsiyet, öğretmenliği tercih etme nedeni, öğretmenliği tercih sırası, yaşamını daha çok nerede geçirdiği, öğretmenliği tavsiye etme durumu ve branş gibi bazı değişkenler bakımından incelenmiş ve buna yönelik bulgular aşağıda verilmiştir.

Tablo 8. Bazı değişkenlere göre uzun erimlilik eğilimleri

\begin{tabular}{|c|c|c|c|c|c|c|c|c|}
\hline \multirow{11}{*}{ 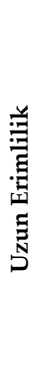 } & Değişken & Grup & $\mathbf{n}$ & $X$ & Ss & $t$ & Sd & $\mathrm{p}$ \\
\hline & \multirow[t]{2}{*}{ Cinsiyet } & Kadın & 230 & 3,4449 & ,81973 & \multirow[t]{2}{*}{165} & \multirow[t]{2}{*}{378} & \multirow[t]{2}{*}{869} \\
\hline & & Erkek & 150 & 3,4309 & 79068 & & & \\
\hline & \multicolumn{2}{|c|}{ Öğretmenliği tercihİsteğimle } & 245 & 3,5168 & ,79256 & \multirow[t]{2}{*}{2,538} & \multirow[t]{2}{*}{378} & \multirow[t]{2}{*}{,012 } \\
\hline & etme nedeni & Diğer (Çevre/Aile) & 135 & 3,2988 & ,81790 & & & \\
\hline & Öğretmenlik & İlk 5 Tercih & 240 & 3,5041 & ,82660 & \multirow[t]{2}{*}{2,056} & \multirow[t]{2}{*}{378} & \multirow[t]{2}{*}{,040 } \\
\hline & kaçıncı tercih & 6 ve sonrası tercih & 140 & 3,3283 & ,76343 & & & \\
\hline & \multirow{2}{*}{$\begin{array}{l}\text { Yaşamını daha çok } \\
\text { nerede geçirdiği }\end{array}$} & Köy/Kasaba/İlçe & 171 & 3,4271 & ,83532 & \multirow[t]{2}{*}{,- 267} & \multirow[t]{2}{*}{378} & \multirow[t]{2}{*}{,790 } \\
\hline & & Şehir/Büyükşehir & 209 & 3,4494 & 78563 & & & \\
\hline & \multirow{2}{*}{$\begin{array}{l}\text { Öğretmenliği } \\
\text { tavsiye etme }\end{array}$} & Evet & 276 & 3,4811 & ,81013 & \multirow[t]{2}{*}{1,646} & \multirow[t]{2}{*}{378} & \multirow[t]{2}{*}{ 101 } \\
\hline & & Hayır & 104 & 3,3285 & ,79319 & & & \\
\hline
\end{tabular}

Tablo 8'de görüldüğü gibi öğretmen adaylarının uzun erimlilik konusundaki görüşleri öğretmenliği tercih etme nedenine göre kendi isteğiyle tercih edenlerin lehine; öğretmenliği tercih sırasına göre ilk 5 tercihi olanların lehine anlamlı olarak farklılaşmaktadır. Buna karşın cinsiyet, öğretmenliği tavsiye etme durumu, yaşamını geçirdiği yer bakımından ise anlamlı olarak farklılaşmamaktadır. 
Tablo 9. Bölümlere Göre Uzun Erimlilik

\begin{tabular}{llllll}
\hline & $\mathbf{N}$ & $\mathbf{X}$ & Ss & F & p \\
\hline 1. Türkçe Ö. & 34 & 3,53 &, 68 & & \\
2. Sosyal Bilgiler Ö. & 115 & 3,50 &, 91 & & \\
3. İlköğretim Mat. Ö. & 53 & 3,53 &, 49 & 1,523 &, 182 \\
4 Fen Bilgisi Ö. & 49 & 3,51 &, 82 & & \\
5. Sinıf Ö. & 96 & 3,32 &, 80 & \\
6. BÖTE Ö. & 33 & 3,18 &, 88 & \\
Toplam & 380 & 3,43 &, 80 & \\
\hline
\end{tabular}

Tablo 9’ da görüldüğ̈̈ gibi branşlarına göre katılımcıların görüşleri arasında anlamlı fark saptanmamıştır.

\section{Öğretmenlik Mesleğine Yönelik Tutuma İlişkin Bulgular}

Araştırma kapsamına kendilerinden veri toplanan öğretmen adaylarının mesleğe yönelik tutumları hesaplanmış ve bulgular aşağıda verilmiştir.

Tablo 10. Öğretmenlik Mesleğine Yönelik Tutum

\begin{tabular}{lllll}
\hline Ölçek & $\mathbf{n}$ & $\mathbf{X}$ & Ss & Düzey \\
\hline Öğretmenlik Mesleğine Yönelik Tutum Toplam & 380 & 3,60 &, 75 & Yüksek \\
\hline
\end{tabular}

Tablo 10'da görüldüğü gibi araştırmaya katılan öğretmen adaylarının öğretmenlik mesleğine yönelik tutumları $(X=3,60)$ düzeyindedir. Buna göre öğretmen adayları öğretmenlik mesleğine yönelik yüksek düzeyde olumlu tutuma sahiptirler.

Araştırmada, öğretmen adaylarının öğretmenlik mesleğine yönelik tutumları cinsiyet, öğretmenliği tercih etme nedeni, öğretmenliği tercih sırası, yaşamını daha çok nerede geçirdiği, öğretmenliği tavsiye etme durumu ve branş gibi bazı değişkenler bakımından incelenmiş ve buna yönelik bulgular aşağıda verilmiştir.

Tablo 11. Bazı değişkenlere göre öğretmenlik mesleğine yönelik tutum

\begin{tabular}{|c|c|c|c|c|c|c|c|c|}
\hline \multirow{9}{*}{ 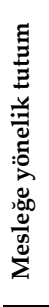 } & Değişken & Grup & $\mathbf{n}$ & $X$ & Ss & $t$ & Sd & p \\
\hline & \multirow{2}{*}{ Cinsiyet } & Kadın & 230 & 3,69 & ,78 & 3,100 & 378 &, $002^{*}$ \\
\hline & & Erkek & 150 & 3,45 & 67 & & & \\
\hline & \multicolumn{2}{|c|}{ Öğretmenliği tercihİsteğimle } & 245 & 3,77 & ,76 & 6,314 & 378 &, $000^{*}$ \\
\hline & etme nedeni & Diğer (Çevre/Aile) & 135 & 3,28 & ,61 & & & \\
\hline & Öğretmenlik & İlk 5 Tercih & 240 & 3,69 & ,75 & 3,142 & 378 &, $002^{*}$ \\
\hline & kaçıncı tercih & 6 ve sonrası tercih & 140 & 3,44 & ,72 & & & \\
\hline & \multirow{2}{*}{$\begin{array}{l}\text { Yaşamını daha çok } \\
\text { nerede geçirdiği }\end{array}$} & Köy/Kasaba/İlçe & 171 & 3,61 & ,72 & ,234 & 378 & 815 \\
\hline & & Şehir/Büyükşehir & 209 & 3,59 & ,77 & & & \\
\hline
\end{tabular}




\begin{tabular}{llllllll}
\hline Öğretmenliği & Evet & 276 & 3,73 &, 75 & 6,186 & 378 &, $000^{*}$ \\
tavsiye etme & Hayır & 104 & 3,22 &, 61 & & & \\
\hline
\end{tabular}

Tablo 11'de görüldüğü gibi öğretmen adaylarının öğretmenlik mesleğine yönelik tutumları cinsiyete göre kadınların lehine; öğretmenliği tercih etme nedenine göre kendi isteğiyle tercih edenlerin lehine; öğretmenliği tercih sırasına göre ilk 5 tercihi olanların lehine; öğretmenliği tavsiye etme durumuna göre tavsiye edenlerin lehine anlamlı olarak farklılaşmaktadır. Yaşamını geçirdiği yer bakımından ise farklılaşmamaktadır.

Tablo 12. Bölümlere göre öğretmenlik mesleğine yönelik tutumlar

\begin{tabular}{|c|c|c|c|c|c|c|}
\hline & $\mathbf{N}$ & $X$ & Ss & F & $\mathrm{p}$ & Farkın kaynağı \\
\hline 1. Türkçe Ö. & 34 & 3,48 & 67 & \multirow{7}{*}{4,823} & \multirow{7}{*}{,000 } & \multirow{7}{*}{$3<2,4,5$} \\
\hline 2. Sosyal Bilgiler Ö. & 115 & 3,71 & ,73 & & & \\
\hline 3. İlköğretim Mat. Ö. & 53 & 3,23 & ,58 & & & \\
\hline 4. Fen Bilgisi Ö. & 49 & 3,79 & ,74 & & & \\
\hline 5. Sinıf Ö. & 96 & 3,67 & ,81 & & & \\
\hline 6. BÖTE Ö. & 33 & 3,37 & 69 & & & \\
\hline Toplam & 380 & 3,60 & ,75 & & & \\
\hline
\end{tabular}

Tablo 12' de görüldüğü gibi branşlarına göre katılımcıların görüşleri arasında anlamlı fark saptanmıştır. Çoklu karşılaştırma testlerine (LSD) göre ilköğretim matematik bölümünde okuyan öğretmen adaylarının mesleğe karşı tutumları diğer bölümlerdekilere göre daha düşüktür.

\section{Belirsizlikten Kaçınma, Uzun Erimlilik ve Mesleki Tutum Arasındaki İlişki}

Öğretmen adaylarının öğretmenlik mesleğine ilişkin tutumları ile belirsizlikten kaçınma ve uzun erimlilik kültür değerleri arasındaki ilişkiyi ortaya koymak amacıyla alt grup ve üst grupların ortalamaları hesaplanmış ve aşağıdaki tabloda verilmiştir.

Tablo 13. Belirsizlikten Kaçınma, Uzun Erimlilik ve Mesleki Tutum Arasındaki İlişki

\begin{tabular}{lllllll}
\hline & Mesleki Tutumları & N & Min & Max & X & Ss \\
\hline \multirow{2}{*}{ Belirsizlikten Kaçınma } & Alt Grup & 91 & 1,35 & 5,00 & 3,45 &, 71 \\
& Üst Grup & 124 & 2,30 & 5,00 & 3,79 &, 77 \\
\multirow{2}{*}{ Uzun Erimlilik } & Alt Grup & 77 & 1,35 & 4,83 & 3,31 &, 63 \\
& Üst Grup & 142 & 2,26 & 5,00 & 3,88 &, 76 \\
\hline
\end{tabular}


Tablo 13'de görüldüğü gibi belirsizlikten kaçınma boyutunda alt grubun öğretmenlik mesleğine yönelik tutum ortalaması $(X=3,45)$ iken üst grubun ortalaması $(X=3,79)$ olarak hesaplanmıştır. Ayrıca uzun erimlilik boyutunda alt grubun öğretmenlik mesleğine yönelik tutum ortalaması $(X=3,31)$ iken üst grubun ortalaması $(X=3,88)$ olarak hesaplanmıştır. Buna göre yüksek düzeyde belirsizlikten kaçınma eğiliminde olan öğretmen adaylarının mesleki tutumlarının daha olumlu olduğu; benzer şekilde, uzun erimli kültür değerlerine yüksek düzeyde sahip olan katılımcıların öğretmenlik mesleğine yönelik olumlu tutumlarının daha yüksek olduğu söylenebilir.

\section{Sonuç ve Tartışma}

İnsanların alg1 ve tutumlarının bireysel değerlerinden beslendiği, bireysel değerlerin ise makro anlamda ulusal kültür değerleriyle sosyalizasyon sürecinde şekillendiği ileri sürülebilir. Bu varsayımdan hareketle bu çalışma, öğretmen adaylarının uzun erimlilik ve belirsizlikten kaçınma kültür değerlerinin onların öğretmenlik mesleğine ilişkin tutumlarının şekillenmesinde belirleyici olabileceğini ortaya koymaya çalışmaktadır. Bir toplumdaki mevcut belirsizlik hissi ve onunla baş etme biçimleri, toplumun üyeleri arasında paylaşılan bir olgu, toplumsallaşma yoluyla öğrenilen kültürel kodlardır. Temelleri itibariyle ussal olmayan bu tür duygu durumları aile, okul ve devlet gibi kurumlar tarafindan aktarılmakta ve beslenmekte zamanla kolektif davranış kalıplarına dönüşmektedirler (Hofstede vd., 2010).

Araştırmada elde edilen sonuçlara göre öğretmen adayları orta düzeyde belirsizlikten kaçınma eğilimine sahiptirler. Buna göre öğretmen adaylarının belirsiz veya bilinmeyen durumlar karşısında hissettikleri tehdit ve endişeden kurtulmanın bir yolu olarak açk talimat ve prosedürleri önemsedikleri söylenebilir. $\mathrm{Bu}$ bulguyu destekleyen ulusal ve uluslararası araştırmalar mevcuttur. House, vd., (2004) tarafından yürütülen GLOBE araştırmasında Arap ülkeleriyle aynı kümede yer alan Türkiye, orta düzeyde belirsizlikten kaçınma kültür değerine sahip olarak değerlendirilmiştir. Yıldırım (2016) çalışmasında öğretmen adaylarının belirsizlikten kaçınmaya ilişkin algılarının orta düzeyde olduğunu tespit etmiştir. Aday öğretmenlere ilişkin benzer bir 
bulguyu Korkut ve Keskin (2015) de paylaşmıştır. Öte yandan okul müdürlerinin (Neyişçi, 2008; Polat ve Göktürk, 2005) ve öğrenci velilerinin (Macit, 2010) orta düzeyde belirsizlikten kaçınma değerlerine sahip olduklarına ilişkin araştırma sonuçları söz konusudur.

Araştırmanın bu bulgusu, uluslararası düzeyde çok sık referans alınan Hofstede'nin araştırmasında Türkiye'ye yönelik tespit edilen bulgusuyla örtüşmemektedir. Nitekim Hofstede'nin araştırma bulgularına göre Türkiye, belirsizlikten kaçınması yüksek düzeyde olan bir kültürel yapıya sahiptir. Söz konusu araştırmada ortalama puan 56 olarak belirlenmiş ve Türkiye 85 puanla 23. sırada yer almıştır (Hofstede vd., 2010, 192). Öte yandan Batır ve Gürbüz (2016) GLOBE araştırmasında Türkiye'ye ilişkin değer tespitinde arada geçen süredeki değişimi ortaya koymayı amaçladığı çalışmasında belirsizlikten kaçınma değerlerinde görece bir düşüş olduğunu belirlemiştir. Kültürün göreli değişimi bu tür araştırmaları boylamsal olarak inceleme uygun hale getirmektedir.

Ulusal alanyazında belirsizlikten kaçınma düzeyinin yüksek olarak tespit edildiği çok sayıda araştırma (Bodur ve Kabasakal, 2002; Dalğalı, 2020; Pasa, Kabasakal ve Bodur, 2001; Sargut, 2015; Saylık, 2017; Turan, Durceylan ve Şişman, 2005; Wasti, 1995) mevcuttur. Diğer taraftan öğretmen adaylarının belirsizlikten kaçınma eğilimleri katılımcların cinsiyet, öğretmenliği tercih etme nedeni, öğretmenliği tercih sırası, öğretmenliği tavsiye etme durumu, yaşamını geçirdiği yer ve branş bakımından anlamlı olarak farklılaşmamaktadır.

Araştırma sonuçlarına göre öğretmen adayları yüksek düzeyde uzun erimlilik değerlerine sahiptirler. Buna göre öğretmen adayları geleceğe ilişkin planlar yapma, pragmatik davranma, modern eğitime bağlı çabaları geleceğe hazırlanmanın bir yolu olarak teşvik etme yönünde uzun zaman odaklı bir kültürel yönelim içerisindedirler. Dalğalı (2020) araştırmasında kamu çalışanı öğretmenlerin yüksek düzeyde uzun erimli bir kültüre sahip olduklarını tespit etmiştir. Ancak araştırmanın bu bulgusu ile Hofstede'nin araştırma bulgusu örtüşmemektedir. Türkiye, Hofstede'nin araştırma bulgularına göre kısa erimlilik boyutunda yer almaktadır (URL-1; Hofstede vd., 2010, 257). McSweeney (2002), Hofstede'nin araştırmasının 1969-1973 yılları arasında yapılmış olmasını zaman bakımından bir sınırlılık olarak değerlendirmektedir. 
Søndergaard (1994), bu yaklaşıma dayanarak toplanan verilerin güncel olmadığını ileri sürmektedir. Kültürün yavaş ancak mutlak anlamda değiştiğinden (Tayeb, 2003) hareketle 1970'lerde yapılmış bir çalışmanın günümüzde geçerliğinin sorgulanması gerektiği (Hill, 1998) ifade edilmektedir. Bu eleştirilere karşı Hofstede (2011) değişimin her ulusta ve kültürde neredeyse aynı hızda gerçekleştiği için kültürler arasındaki farklılığın sürekli biçimde korunabildiğini iddia etmektedir. Dolayısyla son yıllarda yapılan kültür araştımalarının bulgularının Hofstede'nin bulgularıyla örtüşmemesinin hızlanan kültürel değişimler olabileceği düşünülmektedir.

Öğretmen adaylarının uzun erimlilik konusundaki görüşleri öğretmenliği tercih etme nedenine göre kendi isteğiyle tercih edenlerin lehine; öğretmenliği tercih sırasına göre ilk 5 tercihi olanların lehine anlamlı olarak farklılaşmaktadır. Buna karşın cinsiyet, öğretmenliği tavsiye etme durumu, yaşamını geçirmiş olduğu yer ve branş bakımından ise anlamlı olarak farklılaşmamaktadır.

Öğretmen adayları öğretmenlik mesleğine yönelik yüksek düzeyde olumlu tutuma sahiptirler. Öğretmen adaylarının öğretmenlik mesleğine yönelik tutumları cinsiyete göre kadınların lehine anlamlı düzeyde farklılaşmaktadır. Bu durum, toplumsal cünsiyet rolleri bakımından öğretmenlik mesleğinin kadınlar ile daha çok ilişkilendirilmesinin bir yansıması olarak anlamlandırılabilir. Öğretmen adaylarının öğretmenlik mesleğine yönelik tutumları öğretmenliği tercih etme nedenine göre kendi isteğiyle tercih edenlerin lehine anlamlı olarak farklılaşmaktadır. Türkiye'de öğrencilerin meslek seçimlerinde başta ebeveynler olmak üzere öğretmenler ve rehberlik servisi çalışanlarının çoğu zaman ussalliktan uzak, popülizm ve konjonktürel olarak doğrudan müdahalelerin ağır sonuçlarının olduğu bilinmektedir. Bu bakımdan bu dışsal etkilerden uzak öğretmenlik mesleğini kendi arzusuyla tercih edenlerin meslşeki tutumlarının daha olumlu olması anlamlandırılabilir.

Öğretmen adaylarının öğretmenlik mesleğine yönelik tutumları öğretmenler öğretmenliği tercih sırasına göre ilk beş tercihi olanların lehine; öğretmenliği tavsiye etme durumuna göre tavsiye edenlerin lehine anlamlı olarak farklılaşmaktadır. Buna göre öğretmenliği benimseyip, kendisi için doğru meslek seçimi olduğunu düşünen katılımcıların daha olumlu bir tutum içinde oldukları görülmektedir. 
Öğretmen adaylarının öğretmenlik mesleğine yönelik tutumlarının katılımcların yaşamlarını kent veya kırsal bir yerleşim yerinde geçirmiş olma bakımından ise farklılaşmamaktadır. Branş bakımından ise ilköğretim matematik bölümünde okuyan öğretmen adaylarının mesleğe karşı tutumları diğer bölümlerdekilere göre daha düşüktür. Alan olarak gerek kamuya atanmada gerekse de özel sektörde istihdam bakımından görece avantajlı olan ilköğretim matematik bölümü öğrencilerinin öğretmenlik mesleğine ilişkin göreli düşük tutumunun öğrenim görmekte oldukları il ve üniversite deneyimlerinin bir sonucu olabileceği düşünülmektedir.

$\mathrm{Bu}$ araştırma sonucuna göre öğretmen adaylarının öğretmenlik mesleğine karşı yüksek düzeyde olumlu tutuma sahip oldukları saptanmıştır. Bu sonucu destekler biçimde alanyazında araştırma bulgularına rastlamak mümkündür. Araştırmalara göre öğretmenlik mesleğine yönelik tutum, etkili öğretimde önemli bir faktör olarak görülmektedir (Banerjee ve Behera, 2014; Kontaş, 2016; Üstüner, 2017). Bu konuda Bhargava ve Pathy (2014) olumlu tutumun öğretmen yeterliliklerinde belirleyici olduğunu belirtmiştir. Sharbain ve Tan (2012) da öğretmenlerin yeterlilik seviyesinin mesleğe karşı tutumları ile yüksek düzeyde ilişkili olduğunu bulmuştur. Chakraborty ve Mondal (2014) olumlu tutuma sahip öğretmenlerin daha iyi performans ve çaba gösterdiğini bulmuştur. Diğer bazı araştırmalarda da (Bilgin ve Aykaç, 2016; Chakraborty ve Mondal, 2014; Egwu, 2015; Şahin, 2010) öğretmenlik mesleğine yönelik olumlu tutumun öğretmen adaylarının farklı ortamlarda etkili bir şekilde öğretmelerini sağladığ 1 sonucuna varılmıştır. Bu nedenle öğretmenlik mesleğine yönelik olumlu tutumlar, etkili öğretimin önemli bir unsuru olarak görülebilir. Öğretmen adaylarının mesleğe karşı tutumlarını büyük oranda lisans sürecinde geliştirdikleri (Akbulut ve Karakuş, 2011; Alkhateeb, 2013; Üstüner, 2017) dikkate alındığında bu süreçteki eğitimin önemi ortaya çıkmaktadır. Öğretmen yetiştirme programları, öğretmen adaylarının öğretmenlik mesleğine yönelik olumlu tutumlar kazanmasına yönelik unsurlar içermelidir. Bu bağlamda Alkhateeb (2013) öğretmen adaylarının öğretmenlik mesleğine yönelik tutumlarının akademik başarılarını etkilediğini saptamıştır. Chakraborty ve Mondal (2014) da öğretmen adaylarının mesleğe karşı tutumları ile akademik nitelikleri 
arasında önemli bir ilişki bulmuştur. Ülkemizde öğretmenlik mesleğine yönelik tutum üzerine yapılan araştırmalar (Çetinkaya, 2009; Kaya ve Büyükkasap, 2005; Şahin, 2010; Tanel, Şengören ve Tanel, 2007; Tösten, Han ve Çakmak, 2018; Üredi, 2017; Üstün, Erkan ve Akman, 2004; Yıldırım, 2012) öğretmen adaylarının mesleğe karşı olumlu bir tutum taşıdıklarını ortaya koymaktadırlar. Bu araştırma bulguları öğretmen adaylarının mesleğe karşı olumlu tutumunun hem akademik anlamda hem de sosyo-kültürel gelişimlerine katkı sağlayabilecek özellikler taşıdığını göstermektedir. Buna göre mesleğe karşı tutumun kültürel değerler ile olan ilişkisi belirgin hale gelmektedir.

Kartal, vd., (2012) öğretmen adaylarının öğretmenlik mesleğine yönelik tutumları ile cinsiyet, genel akademik ortalama, ailenin aylık geliri ve üniversite öncesi nerede yaşadıkları ile ilgili puanları arasında istatistiksel olarak anlamlı bir fark olmadığını saptamıştır. Ancak birtakım araştırmalar (Atalmış ve Köse, 2018; Baş ve Sarigöz, 2018; Fadlelmula, 2013; Yıldırım, 2012) kadınların öğretmenlik mesleğine yönelik daha olumlu bir tutuma sahip olduklarını sonucuna ulaşmışlardır.

Alanyazında ulaşılan araştırmalarda öğretmenlik mesleğine yönelik tutumun birçok değişken ile ilişkili olduğu ortaya konulmaktadır. Bu bağlamda, Bektaş ve Nalçacl, (2012) öğretmen adaylarının kişisel değerlerinin öğretmenlik mesleğine yönelik tutumlarını yordadığını saptamıştır. Araştırmalarda öğretmenlik mesleğine yönelik tutumların öğretmenliğe yönelik yeterlilik algısı ile pozitif bir ilişkisi olduğu tespit edilmiştir (Akbaba, 2013; Bhargava ve Pathy, 2014; Sharbain ve Tan, 2012). Benzer şekilde öğretmenlik mesleğine yönelik tutum ile iletişim becerileri (Yeşil, 2010); yaşam doyumu (Şahin, 2010); öz-yeterlik inançları (Uyanık, 2016; Üstüner, 2017) arasında pozitif yönde anlamlı bir ilişki bulunurken, yabancılaşma ile negatif bir ilişki (Çağlar, 2013) saptanmıştır. Dolayısıyla öğretmenlik mesleğine yönelik olumlu tutum; öz yeterlilik, iletişim becerileri, yaşam doyumu ve öz-yeterlik gibi birçok değişkenle ilişkilidir. Bir toplumda mesleki belirlenim ve tutumların ulusal ve bireysel kültürel kodların etkisinde şekillendiği varsayımından hareketle bu araştırma da öğretmenlik mesleğine ilişkin tutumun belirsizlikten kaçınma ve uzun-kısa erimlilik kültürel değerlerle ilişkili olduğu ortaya koymaktadır. 
Öğretmen adaylarının öğretmenlik mesleğine tutumları ile belirsizlikten kaçınma eğilimleri arasında alt ve üst grupların ortalamalarında fark saptanmıştır. Buna göre yüksek düzeyde belirsizlikten kaçınma eğiliminde olan öğretmen adaylarının mesleki tutumlarının daha olumlu olduğu belirlenmiştir. Bu durum Türkiye'nin sosyolojik yapısına özgü bir bulgu olarak dikkat çekicidir. Öğretmenlik mesleğinin genel anlamda diğer meslek gruplarına göre geniş bir istihdam alanına sahip olması ve kamuda emekliliğe kadar kadrolu bir iş güvencesi ile özdeş düşünülmesinin, geleceğe ilişkin belirsizlikten kaynaklı stres ve gerilimi bir kısım da olsa hafiflettiği düşünülmektedir. Belirsizliğin hakim olduğu Türkiye'nin kültürel yapısı, meslek tercihlerinde devlet güvencesi-kadrolu iş anlayışı ve arayışına fazlaca anlam yüklemeyi doğurmaktadır. Bu nedenle Türkiye'de kamusal istihdam alanlarında performansa dayalı ücret, sözleşmelilik gibi yapısal reform girişimleri her zaman ciddi direnişlere maruz kalmıştır. Bu tür toplumlarda kariyerde istikrar sağlama ve iş yaşamında devamlılık güçlü beklentilerdir. Bu sayede belirsizlikten kaynaklı güvensizlik ve tehdit algısı, stres ve endişenin önüne geçilir.

Belirsizlikten kaçınma değerlerinin düşük olduğu öğretmen adaylarının öğretmenlik mesleğine yönelik tutumları görece daha düşüktür. BK'nın düşük olduğu toplumlarda iş değiştirmeler sık olmakta ve ortalama istihdam süresi kısa olmaktadır. Bu değerler düşünüldügünde BK değerleri düşük olan öğretmen adaylarının öğretmenlik mesleğine yönelik yüksek bir olumlu tutum geliştirmemeleri anlaşılırlık kazanmaktadır. Bu tür toplumlarda lisans diploması, meslekler arası geçiş için gerekli ve çoğu zaman da yeterli bir belgedir.

Öğretmen adaylarının öğretmenlik mesleğine yönelik tutumları ile uzun erimlilik kültür değerleri arasında alt ve üst grupların ortalamalarında fark saptanmıştır. Buna göre uzun erimli kültür değerlerine yüksek düzeyde sahip olan katılımcıların öğretmenlik mesleğine yönelik olumlu tutumları daha yüksektir. Öğretmen adaylarından sebat ve kararlılık, tasarruflu oluş, istikrar gibi değerlere sahip olanların öğretmenlik mesleğine yönelik tutumları daha olumlu bulunmuştur. Bu katılımcılar mevcut geleneksel değerleri daha modern bir yapıya dönüştürme çabası içerisindedirler. Öğretmenlik mesleğine 
yönelik görece daha olumsuz tutuma sahip olan öğretmen adaylarının ise kısa dönem erimli değerlere sahip oldukları görülmektedir. Toplumsal değişimi şüpheyle izleyen bir kültürel yaklaşıma sahip olan kısa erimli bireylerin zamana bağlı gelenek ve normları koruma eğilimlerinin güçlü olduğu belirtilebilir.

Araştırma sonuçlarından hareketle, bireysel ve kültürel değerler ile mesleki tutuma yönelik çalışmalara ihtiyaç olduğu söylenebilir. Kültürün, özellikle küreselleşmenin ve teknolojinin etkisiyle zaman içerisinde değişen bir olgu olduğundan araştırmacılara, boylamsal çalışmalar yapılarak değişimin hızı ve yönü hakkında araştırmalar yapmaları önerilmektedir. Bu tür araştırmaların öğretmen adayları, aday öğretmenler ve kadrolu öğretmenleri bir arada incelenebilmesine imkan verecek şekilde yapılması önerilmektedir. Araştırmada öğretmen adaylarının belirsizlikten kaçınmaya ilişkin yüksek algı düzeylerinden hareketle milli eğitim mevzuatının, talimat ve yönergelerin, kuralların apaçıklığını gösteren/tartışan ders, etkinlik ve uygulamalar (staj sırasında) sağlanmalı, böylece öğretmen adaylarının kaygıları hafifletilmelidir.

Araştırmanın en önemli sınırlılığı Hofstede'nin kültür modelinin ve ölçme aracının zaman bakımından eski olması, geçerliğinin ve genellenebilirliğinin eleştirilerin odağında olmasıdır. Öte yandan bu çalışma kesitsel bir çalışmadır. Kültürün, bilim ve teknolojinin hızına bağlı olarak son zamanlarda daha hızlı değiştiği düşünüldüğünde kültürel çalışmalarda boylamsal yaklaşımın daha sağlıklı sonuçlar üretebileceği ileri sürülebilir. 
EXTENDED ABSTRACT

\title{
The Relationship between Attitude towards Teaching Profession and Uncertainty Avoidance and Long-Term Orientation as Cultural Values
}

\author{
Ahmet Saylık- Bünyamin Han \\ Siirt University-Dumlupinar University
}

\section{Introduction}

It is possible to mention some unique features of the teaching profession. It is a profession that requires sacrifice, sincerity and extra effort. For this reason, it is very important for a successful teacher to love his profession and have a positive attitude towards the profession. It is possible to talk about many factors that affect the effectiveness of teachers. Both teaching competencies and personal characteristics of teachers play an important role in the process. Although the professional attitudes of individuals in a society, the meaning they attribute to work and business life and their expectations seem individual, it is thought that they are fed by the macro-level social culture structure and values and this is formed during the socialization process. In this sense, it is thought that national cultural values affect the range of professional concerns, attitudes and meanings, as well as the level of tolerance of the society against uncertainty and how it gives meaning and value to time (past, present and future) in its life.

\section{$\operatorname{Aim}$}

The main purpose of this research is to reveal the relationship between pre-service teachers' attitudes towards the teaching profession and their levels of uncertainty avoidance and long-rangeness as cultural values. In addition, in the context of gender roles, depending on the fact that the teaching profession is considered more as a female profession, it was examined whether the genders of the teacher candidates reveal a significant difference in both cultural variables and teaching profession 
attitudes. It is among the sub-objectives of the research to reveal the determinants of the personal preferences and characteristics of the participants, such as in which order they prefer teaching, whether they adopt teaching or not, in which field/department they are teacher candidates, on the attitude towards the teaching profession. Similarly, it was thought that the participant's life in a settlement mostly affected their social socialization, and it was thought that it might play a role in the formation of cultural values and the effects in the research were tried to be revealed.

\section{Method}

This research is a descriptive research and the "relational survey" design was used in the research. In this context, the relationship between the cultural values of uncertainty avoidance and long-term values with teaching attitude was examined. The "Individual Cultural Values Scale" (CVSCALE), which was developed by Yoo, Donthu and Lenartowicz (2011) and adapted into Turkish by Saylik (2019), was used. Also, "Attitude Scale Towards Teaching" developed by Erkuş, Sanlı, Bağlı and Güven (2000) was used to collect data in the study. The target population of the research consists of students studying at Siirt University Faculty of Education. According to the current data obtained from Siirt University student affairs, 1867 students are studying in the Departments of Classroom, Science, Turkish, Primary Education Mathematics, Social Studies Education and Computer and Instructional Technologies Education within the Faculty of Education. In the research, "stratified sampling" method was applied to collect the necessary data. Research data were analyzed through computer package programs. First, the normality of the data was tested. Accordingly, the normality was calculated for the attitude towards the profession as (Skewness $=, 137$; Kurtosis $=-, 876$ ); for uncertainty avoidance (Skewness $=-.027$; Kurtosis $=$ -.466); for long-term orientation (Skewness = -.170; Kurtosis $=-.461$ ). Since these values are between -2 and +2 , it is assumed that the data show a normal distribution. Therefore, parametric tests ( $t$-Test, ANOVA) were used in the analyses. The relative size of the number of participants in 
the study ( $\mathrm{n}=380)$ also strengthened the opinion that the data were normally distributed.

The reliability of the data was demonstrated by calculating the Cronbach's Alpha coefficients. Accordingly, Cronbach's Alpha coefficient is .90 for the attitude towards the profession; .65 for uncertainty avoidance; Calculated as .70 for long-term orientation. These values are in the acceptable range.

\section{Conclusion and Discussion}

It can be argued that people's perceptions and attitudes are fed by their individual values, and individual values are shaped in the macro sense in the process of socialization with national cultural values. Based on this assumption, this study tries to reveal that prospective teachers' longterm orientations and uncertainty avoidance cultural values can be determinative in shaping their attitudes towards the teaching profession.

According to the results obtained in the research, pre-service teachers have a moderate tendency to avoid uncertainty. Accordingly, it can be claimed that pre-service teachers care about clear instructions and procedures as a way of getting rid of the threat and anxiety they feel in the face of uncertain or unknown situations. The pre-service teachers have a long-term cultural orientation to make plans for the future, act pragmatically, and encourage efforts related to modern education as a way of preparing for the future.

Teacher candidates have a high level of positive attitude towards the teaching profession. The attitudes of teacher candidates towards the teaching profession differ significantly in favor of women according to gender. This situation can be interpreted as a reflection of the fact that the teaching profession is more associated with women in terms of gender roles. Based on the results of the research, it can be said that there is a need for studies on individual and cultural values and professional attitude. Since culture is a phenomenon that changes over time, especially with the effect of globalization and technology, researchers are advised to conduct longitudinal studies about the speed and direction of change. It is recommended that such studies be conducted in a way that allows prospective teachers, prospective teachers and permanent 
teachers to be examined together. In the study, lessons, activities and practices (during the internship) that show/discuss the clarity of the national education legislation, instructions and directives, rules should be provided based on the high perception levels of teacher candidates about avoiding uncertainty, so that the anxiety of the teacher candidates should be alleviated.

\section{Kaynakça/References}

Akbaba, B. (2013). The attitudes of pre-service social studies teachers' towards teaching profession and their self-efficacy about using instruction materials. Mevlana International Journal of Education, 3(2), 157-169.

Akbulut, Ö. E. ve Karakuş, F. (2011). The investigation of secondary school science and mathematics pre-service teachers' attitudes towards teaching profession. Educational Research and Reviews, 6(6), 489-496.

Alkhateeb, H. M. (2013). Attitudes towards teaching profession of education students in Qatar. Comprehensive Psychology, 2, 1-3.

Andronache, D., Bocoş, M., Bocoş, V. ve Macri, C. (2014). Attitude towards teaching profession. Procedia-Social and Behavioral Sciences, 142, 628632.

Atalmış, E. ve Köse, A. (2018). Turkish prospective teachers' attitudes towards the teaching profession: A meta-analysis study. Eğitimde ve Psikolojide Ölçme ve Değerlendirme Dergisi, 9(4), 393-413.

Babu, B. P. ve Raju, T. J. M. S. (2013). Attitude of student teachers towards their profession. International Journal of Social Science $\mathcal{E}$ Interdisciplinary Research, 2(1), 1-6.

Banerjee, S. ve Santosh, K. B. (2014). An investigation into the attitude of secondary school teachers towards teaching profession in Purulia District of West Bengal, India. International Journal of Academic Research in Education and Review, 2(3), 56-63.

Barwal, S. K. (2011). Attitude of secondary school teachers towards their teaching profession. International Journal of Education $\mathcal{E}$ Allied Sciences, 3(1), 63-68.

Baş, M. ve Sarigöz, O. (2018). An examination of teacher candidates' attitudes towards teaching profession. International Journal of Educational Administration and Policy Studies, 10(4), 25-32. 
Batır, F. ve Gürbüz, S. (2016). Türkiye'nin toplumsal kültür eğilimleri: Globe araştırmasından sonra ne değişti? 24. Ulusal Yönetim ve Organizasyon Kongresi Bildiriler Kitabı, 427-438, 28-31 Mayıs 2016, İstanbul.

Bektaş, F. ve Nalçaci, A. (2012). The relationship between personal values and attitude towards teaching profession. Educational Sciences: Theory and Practice, 12(2), 1244-1248.

Bhargava, A. ve Pathy, M. (2014). Attitude of student teachers towards teaching profession. Turkish Online Journal of Distance Education, 15(3), 27-36.

Bilgin, H. ve Aykaç, N. (2016). Pre-service teachers' teaching-learning conceptions and their attitudes towards teaching profession. Educational Process: International Journal, 5(2), 139-151.

Bodur, M. ve Kabasakal, H. (2002). Türkiye Arap kümesinde kurumsal kültür: Globe araştırması, Başkent Üniversitesi Yönetim Araştırmaları Dergisi, 2(1), 5-22.

Chakraborty, A. ve Mondal, B. C. (2014). Attitude of prospective teachers towards teaching profession. American Journal of Social Sciences, 2(6), 120-125.

Cristina-Corina, B. ve Valerica, A. (2012). Teachers' perceptions and attitudes towards professional activity. Procedia-Social and Behavioral Sciences, $51,167-171$.

Çağlar, C. (2013). The relationship between the levels of alienation of the education faculty students and their attitudes towards the teaching profession. Educational Sciences: Theory and Practice, 13(3), 1507-1513.

Çetinkaya, Z. (2009). Türkçe öğretmen adaylarının öğretmenlik mesleğine ilişkin tutumlarının belirlenmesi. Ilkogretim Online, 8(2), 298-305.

Dalğalı, F. (2020). Okul müdürlerinin dönüşümcü liderlik yaklaşımları ile Hofstede'nin ulusal kültür boyutları arasındaki ilişkisi. (Yayımlanmamış yüksek lisans tezi). Siirt Üniversitesi, Sosyal Bilimler Enstitüsü, Siirt.

Egwu, S. O. (2015). Attitude of students towards teaching profession in Nigeria: Implications for education development. Journal of Education and Practice, 6(29), 21-25.

Erkuş, A., Sanlı, N., Bağlı, M. T. ve Güven, K. (2000). Öğretmenliğe ilişkin tutum ölçeği geliştirilmesi. Eğitim ve Bilim, 25(116), 27-33.

Fadlelmula, F. K. (2013). Attitudes of pre-service teachers towards teaching profession. Turkish Journal of Education, 2(4), 55-63. 
Güneyli, A. ve Aslan, C. (2009). Evaluation of Turkish prospective teachers' attitudes towards teaching profession (Near East University case). Procedia-Social and Behavioral Sciences, 1(1), 313-319.

Hill, C.W. (1998). International business: Competing in the global marketplace. 2nd ed. Boston, USA: Irwin/McGraw-Hill.

Hofstede, G. (1980). Motivation, leadership, and organization: Do American theories apply abroad? Organizational Dynamics, 9(1), 42-63.

Hofstede, G. (1983). The cultural relativity of organizational practices and theories. Journal of International Business Studies, Special Issue on Cross- Cultural Management, 14(2), 75-89.

Hofstede, G. (2001). Culture's consequences: Comparing values, behaviors, institutions and organizations across nations, 2. Edition. Sage Publication.

Hofstede, G. (2011). Dimensionalizing cultures: The Hofstede model in context. Online Readings in Psychology and Culture, 2(1), 1-26.

Hoftede, G., Hofstede, G. J. ve Minkov, M. (2010). Cultures and organizations: Software of the mind: intercultural cooperation and its importance for survival. McGraw-Hill.

House, R. J., Hanges, P. J., Javidan, M., Dorfman, P. W. ve Gupta, V. (Eds.). (2004). Culture, leadership, and organizations: The GLOBE study of 62 societies. Sage publications.

Javidan, M. ve House, R. J. (2001). Cultural acumen for the global manager: Lessons from project GLOBE. Organizational Dynamics, 29(4), 289-305.

Kartal, T., Kaya, V. H., Öztürk, N. ve Ekici, G. (2012). The exploration of the attitudes of the science teacher candidates towards teaching profession. Procedia-Social and Behavioral Sciences, 46, 2759-2764.

Kaya, A. ve Büyükkasap, E. (2005). Physics student teachers' profiles, attitudes and anxiety toward teaching profession: An Erzurum sample. Kastamonu Education Journal, 13(2), 367-380.

Kontaş, H. (2016). The effect of an education-themed movie on the academic motivation of teacher candidates and their attitude towards teaching profession. Journal of Education and Training Studies, 4(6), 93-103.

Korkut, A. ve Keskin, İ. (2015). Öğretmen adaylarının belirsizlikten kaçınma düzeylerine ilişkin karşılaştırmalı bir analiz. Electronic International Journal of Education, Arts, and Science (EIJEAS), 1(2), 31-57.

Macit, G. (2010). İletişim tarzları üzerinde kültürel değerlerin etkisi: Mehmet Akif Ersoy üniversitesi öğrencileri üzerinde bir araştırma (Yüksek lisans tezi). Sosyal Bilimler Enstitüsü, Mehmet Akif Ersoy Üniversitesi, Isparta. 
McSweeney, B. (2002). Hofstede's Model of national cultural differences and their consequences: A triumpf of faith $\mathcal{E}$ a failure of analyses. London: Sage Publications.

Musa, A. ve Bichi, A. A. (2015). Assessment of prospective teachers' attitudes towards teaching profession: The case of Northwest University, KanoNigeria. IOSR Journal of Research and Method in Education, 5(3), 17-24.

Mosakowski, E. ve Earley, P. C. (2000). A selective review of time assumptions in strategy research. Academy of Management Review, 25(4), 796-812.

Neyişçi, N. B. (2008). Türkiye'deki mesleki eğitim ve öğretimin güçlendirilmesi projesi (Megep) içindeki okul yöneticilerinin belirsizlikten kaçımma davranışlarını gerçekleştirme düzeyleri. (Yayımlanmamış yüksek lisans tezi). Hacettepe Üniversitesi, Sosyal Bilimler Enstitüsü, Ankara.

Oğuz, E. ve Kalkan, M. (2011). Examining teacher candidates' attitudes towards teaching profession and pupil control ideology. International Online Journal of Educational Sciences, 3(3), 903-917.

Oral, B. (2004). Eğitim fakültesi öğrencilerinin öğretmenlik mesleğine ilişkin tutumları. Eğitim Araştırmaları Dergisi, 15(4), 88-98.

Pancholi, A. ve Bharwad, A. B. J. (2015). Student-teachers' attitude towards teaching profession. International Journal of Research in Humanities and Social Sciences, 3(8), 40-43.

Parvez, M. ve Shakir, M. (2013). Attitudes of prospective teachers towards teaching profession. Journal of Education and Practice, 4(10), 172-178.

Pasa, F., Kabasakal, H. ve Bodur, M. (2001). Society, organisations, and leadership in Turkey. Applied Psychology, 50(4), 559-589.

URL-1. https://geerthofstede.com/landing-pagelturkey.html adresinden erişilmiştir.

Polat, S. ve Göktürk, Ş. D. (2005). Avrupa Birliğine Katılım Sürecinde Okul Müdürlerinin Ulusal Kültür Profili, Halk Kültürlerini Koruma. Yaşatma Ve Geleceğe Aktarma Uluslar Arası, XIV. Ulusal Eğitim Bilimleri Kongresi, Pamukkale Üniversitesi, Denizli.

Robbins, S. P. ve Judge, T. A. (2012). Örgütsel davranış (Organizational Behavior). (İ. Erdem, Trans.), Ankara: Nobel Yayınevi.

Ronen S. (1986). Comparative and multinational management. New York: Wiley. Sargut, A. S. (2015). Kültürler arası farklllaşma ve yönetim. İmge Kitabevi.

Sarkar, D. ve Behera, S. K. (2016). Attitude of college teachers towards teaching profession. American Journal of Educational Research, 4(11), 834-839. 
Saylık, A. (2019). Hofstede'nin kültür boyutları ölçeğinin Türkçe'ye uyarlanması; geçerlik ve güvenirlik çalışması. Uluslararası Türkçe Edebiyat Kültür Eğitim (TEKE) Dergisi, 8(3), 1860-1881.

Sharbain, I. H. A. ve Tan, K. E. (2012). Pre-service teachers' level of competence and their attitudes towards the teaching profession. Asian Journal of Social Sciences \& Humanities, 1(3), 14-22.

Søndergaard, M. (1994). Research note: Hofstede's consequences: A study of reviews, citations and replications. Organization Studies, 15(3), 447-456.

Spears, N., Lin, X. ve Mowen, J. C. (2000). Time orientation in the United States, China, and Mexico: Measurement and insights for promotional strategy. Journal of International Consumer Marketing, 13(1), 57-75.

Şahin, F. S. (2010). Teacher candidates' attitudes towards teaching profession and life satisfaction levels. Procedia-Social and Behavioral Sciences, 2(2), 5196-5201.

Tanel, R., Şengören, S. K. ve Tanel, Z. (2007). Fizik Öğretmen Adaylarının Öğretmenlik Mesleğine İlişkin. Pamukkale Üniversitesi Ĕ̆itim Fakültesi Dergisi, 22(22), 1-9.

Tayeb, M. H. (2003). Cultural Differences across the world, in M.H. Tayeb, (ed.) International Management: Theories and Practices. Harlow: Financial Times Prentice Hall.

Tösten, R., Han, B. ve Çakmak, İ. (2018). Diyarbakır kamu okullarında görevli öğretmenlerin profili. Electronic Journal of Education Sciences, 7(13), 1828.

Trivedi, R. P. (2012). A study of attitude of teachers towards teaching profession teaching at different level. International Multidisciplinary eJournal, 1(5), 24-30.

Turan, S., Durceylan, B. ve Şişman, M. (2005). Üniversite yöneticilerinin benimsedikleri idari ve kültürel değerler. Manas Üniversitesi Sosyal Bilimleri Dergisi, 7(13), 181-202.

Uyanik, G. A. (2016). Investigation of the self-efficacy beliefs in teaching science and attitudes towards teaching profession of the candidate teachers. Universal Journal of Educational Research, 4(9), 2119-2125.

Üredi, L. (2017). Investigating the relationship between job satisfaction levels of the teachers in educational institutions and their attitudes towards teaching profession. Journal of Education and Practice, 8(12), 175-182.

Üstün, E., Erkan, S. ve Akman, B. (2004). Türkiye'de okul öncesi öğretmenliği öğrencilerinin öğretmenlik mesleğine yönelik tutumlarının 
incelenmesi. Kırgizistan-Türkiye Manas Üniversitesi Sosyal Bilimler Dergisi, 10, 129-136.

Üstüner, M. (2017). Personality and attitude towards teaching profession: Mediating role of self efficacy. Journal of Education and Training Studies, 5(9), 70-82.

Wasti, A. (1995). Kültürlerarası farklılaşmanın örgütsel yapı ve davranışa etkileri: karşılaştırmalı bir inceleme. ODTÜ Gelişme Dergisi, 22(4), 503529.

Yaakub, N. (1990). A multivariate analysis of attitude towards teaching. Pertanika, 13(2), 267, 273.

Yeşil, H. (2010). The relationship between candidate teachers' communication skills and their attitudes towards teaching profession. Procedia-Social and Behavioral Sciences, 9, 919-922.

Yıldırım, A. (2016). Öğretmen adaylarının belirsizlikten kaçınma düzeylerinin bazı değişkenler açısından incelenmesi. OPUS Uluslararası Toplum Araştırmaları Dergisi, 6(11), 475-490.

Yıldırım, E. (2012). The investigation of the teacher candidates' attitudes towards teaching profession according to their demographic variables (The sample of Maltepe University). Procedia-Social and Behavioral Sciences, 46, 2352-2355.

Yoo, B., Donthu, N. ve Lenartowicz, T. (2011). Measuring Hofstede's five dimensions of cultural values at the individual level: Development and validation of CVSCALE. Journal of International Consumer Marketing, 23(3-4), 193-210.

\section{Kaynakça Bilgisi / Citation Information}

Saylık, A. ve Han, B. (2021). Kültürel değerler olarak belirsizlikten kaçınma ve uzun erimlilik ile öğretmenlik mesleğine yönelik tutum arasındaki ilişki. OPUS- Uluslararası Toplum Araştırmaları Dergisi, 18(44), 7935-7967. DOI: 10.26466/opus.930935. 